\title{
RELATIONSHIP BETWEEN JOB STRESS, TEMPERAMENT AND DEPRESSIVE SYMPTOMS IN FEMALE NURSES
}

\author{
YOKO KIKUCHI ${ }^{1}$, MAKOTO NAKAYA ${ }^{1,2}$, MIKI IKEDA ${ }^{1}$, SHOKO OKUZUMI ${ }^{1}$, MIHOKO TAKEDA ${ }^{1}$, \\ and MIYOKO NISHI ${ }^{3}$ \\ ${ }^{1}$ Musashino Red Cross Hospital, Tokyo, Japan \\ Department of Psychiatry \\ ${ }^{2}$ Tokyo Medical and Dental University, Tokyo, Japan \\ Faculty of Medicine \\ ${ }^{3}$ Musahino Red Cross Hospital, Tokyo, Japan \\ Department of Nurse
}

\begin{abstract}
Objectives: A casual relationship between temperament, job stress and depressive symptoms has not been established yet. The purpose of this study was to assess the relationships between job stress, temperament and depressive symptoms in female nurses at a Japanese general hospital. Material and Methods: A self-report survey was conducted among 706 nurses. We measured job stress, temperament, and depressive symptoms using the Brief-Job Stress Questionnaire, the TEMPS-A and a screening scale of items from the Ministry of Health, Labour and Welfare of Japan. In order to examine the causal relationship between the measures the stepwise multiple regression and path analyses were used. Results: Depressive symptoms were modestly correlated with job stress $(\gamma=-0.23-0.30)$. Except for hyperthymic temperament measures, the correlations between depressive symptoms and temperament types were significant and moderate $(\gamma=0.36-0.50)$. Overtime, job control as well as depressive and cyclothymic types of temperament were significantly correlated with depressive symptoms $(\beta=0.15, \mathrm{p}<0.05 ; \beta=0.19, \mathrm{p}<0.01 ; \beta=0.26, \mathrm{p}<0.001 ; \beta=0.32, \mathrm{p}<0.001$, respectively). Path-analysis revealed that depressive and cyclothymic types of temperament influenced depressive symptoms both directly $(\beta=0.67$, $p<0.001)$ and indirectly via job stress $(\beta=0.35, p<0.001$ from temperament to job stress; $\beta=0.20, p<0.05$ from job stress to depressive symptoms). Irritable and anxious types of temperament and quantitative job overload did not contribute to the path-analytic model. Conclusions: Health care professionals should consider temperament, especially depressive and cyclothymic types, in order to help employees cope better with job stress factors. We need further research about the effective intervention to help employees better cope with their job stress.
\end{abstract}

Key words:

Bipolar disorder, Depression, Anxiety, Stress, Mood disorder, Health services

\section{INTRODUCTION}

Job stress among hospital employees may adversely affect their mental health. According to previous studies, the risk of mental illness is higher in association with higher job stress. Job stress measured by the Effort Reward Imbalance (ERI) and the Demand Control Support (DCS) was positively associated with depressive symptoms [1-8]. Depression induced by job stress may cause absence from

Received: November 1, 2013. Accepted: March 17, 2014

Corresponding author: Y. Kikuchi, Musashino Red Cross Hospital, Departament of Psychiatry, Kyounancho 1-26-1 Musashinoshi, Tokyo, Japan 180-8610 (e-mail: shinnai@musashino.jrc.or.jp). 
work. In order to investigate what kind of job stress may lead to depression, we examined the relationship between job stress measured by ERI assessment and depressive state among nurses in a Japanese general hospital in a previous study. The results suggested that effort-money (effort-job promotion) imbalance and over-commitment were significantly correlated with depressive state [5].

Concepts of temperament developed by Kraepelin [9], Krechmaer [10], Tellenbach [11] or Shimoda [12] had been studied as personality traits associated with mood disorder. Kraepelin [9], based on his clinical observation, described 4 "fundamental states" of manic depressive illness. Akiskal et al. [13] developed operational criteria to identify the "fundamental states" of bipolar disorder described by Krapelin [9], which was a self-rating version of the TEMPS (Temperament Evaluation of Memphis, Pisa, Paris and San Diego-Autoquestionnaire - TEMPS-A). According to Akiskal et al. [14], temperamental dysregulation can precipitate the development of mood disorders. The TEMPS-A included 5 subscales of affective temperament, i.e., depressive, cyclothymic, hyperthymic, irritable and anxious. The relationship between major depressive or bipolar disorders and temperament has been studied in a Japanese sample [15]. That study suggested that the major depressive and bipolar disorder groups showed significantly higher depressive, cyclothymic and anxious temperament scores than the control group, and that these types of temperament might be risk factors for mood disorders. The relationship between temperament and job stress has been examined by Sakai et al. [16] and Tei-Tominaga et al. [17] in employees of a Japanese company. Sakai et al. [16] have found that temperament predicted a large share of variance in job stress measured by the NIOSH Generic Job Stress Questionnaire $\left(\mathrm{R}^{2}=0.073-0.202\right)$. The influence of temperament varied depending on the kind of job stress. Tei-Tominaga et al. [17] have found that temperament predicted a large share of variance in job stress measured by ERI $\left(\mathrm{R}^{2}=0.142-0.355\right)$, and that

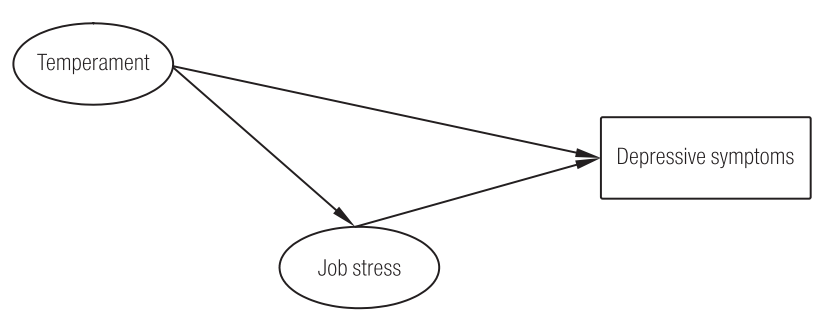

Fig. 1. Conceptual relationships between temperament, job stress and depressive symptoms

both depressive and anxious types of temperament were significantly associated with effort, reward and overcommitment. We have also examined the relationship between temperament and job stress among female nurses in a Japanese general hospital and suggested that depressive temperament significantly influenced all 4 ERI ratios and overcommitment $\left(\mathrm{R}^{2}=0.198-0.283\right)$, whereas anxious temperament influenced only overcommitment $\left(\mathrm{R}^{2}=0.392\right)$ [18]. In the present study, our fundamental assumption was that temperament precedes job stress, and that both temperament and job stress precede depressive symptoms. Therefore, we hypothesized that temperament could predict depressive symptoms either directly or indirectly via job stress (Figure 1).

According to the previous studies, we have already found that the relationship between job stress and depressive symptoms might be influenced by personality [19-21]. TeiTominaga et al. [21] suggest that both, temperament and job stress significantly correlate with depressive symptoms and, more specifically, both cyclothymic and anxious types of temperament are high risk factors for depressive symptoms. However, the causal relationship between temperament, job stress and depressive symptoms has not been fully examined, and the influence of temperament on the relationship between job stress and depressive state has not been well established.

The present study aimed at investigating the fitness of the modeling causality between job stress, temperament and depressive symptoms in female nurses of a Japanese general hospital. 


\section{MATERIAL AND METHODS}

In March 2012, supervisors distributed a questionnaire to all nurses $(\mathrm{N}=706)$ in a general hospital with 611 beds in an urban area of Japan. Specialties of the nurses included in the study were, as follows: intensive care, pediatrics, surgery, oncology, and emergency medicine. Management allowed the nurses to complete the questionnaires during their shifts. The completed questionnaires were returned by 407 out of 706 nurses (response rate $-57.6 \%$ ). Male nurses were excluded from the analysis because only 20 of the $37(54.1 \%)$ male nurses responded. Subjects with missing values for job stress or temperament were also excluded from the study $(\mathrm{N}=57)$. Therefore, the final sample for analysis consisted of 330 female nurses (46.7\%), including those who were managers and middle managers.

The questionnaire collected data concerning age, hours of work (full-time or part-time), shift work, overtime, and job rank (manager, middle manager or staff nurse). Overtime was reported in hours per week. Overtime was voluntary but limited to $45 \mathrm{~h}$ per month. Shift work categories included: "no shift work", "shift work with night shift rotations", or "shift work without night shift rotations". Only managers had a choice in shift assignment. Patients load varied among specialties.

We measured job stress using the Japanese version of the Brief-Job Stress Questionnaire, consisting of 3 subscales; job quantitative overload (3 items), job control ( 3 items) and support from supervisors and coworkers (6 items). The questionnaire contains 12 items with 4-point Likerttype responses (from "agree" = 4 to "disagree" = 1) and it measures job stressors, psychosomatic complaints and support for workers. It has been widely used and established as a method for assessing job stress in Japan. It has been also validated and tested for reliability [22].

Temperament was measured using the Japanese version of TEMPS-A [15], which contains 110 items divided into 5 types of temperament: depressive (21 items), cyclothymic (21 items), hyperthymic (21 items), irritable (for females, 22 items; for males, 21 items) and anxious (26 items). In addition to measuring emotional, cognitive, psychomotor and circadian traits predisposing individuals to major mood disorders, the TEMPS-A also assesses adaptive attributes [14]. For instance, depressive temperament is associated with having a routine, feelings of self-blame, preferring to work for someone else, as well as being shy/nonassertive, sensitive to criticism, self-denying and dependent [14]. For each question, answer "No" scores 1 point and "Yes" 2 points. These scores are added and divided by the number of related questions to represent scores of each temperament.

Depressive symptoms were measured using screening scale with items developed by Fujisawa et al. [23], which is recommended by the Ministry of Health, Labour and Welfare of Japan. A 5-item screen was derived from the Self-rating Depression Scale and the Hospital Anxiety and Depression Scale, using the Composite International Diagnostic Interview as the external criterion. These comprise 5 items, e.g., "Is your life pretty full?". The scale has been validated and tested for reliability [23]. For depression, the sensitivity was 0.705 ; specificity -0.729 and the overall diagnostic power -0.723 . For each answer, "yes" was scored as 0 , and "no" as 1 . The total score represents severity of depressive symptoms.

An explanation of the nature of the survey accompanied the questionnaire, which was anonymous and voluntary. Consent was assumed if participants decided to answer the questionnaire. The study was approved by both, the general hospital's board of directors and its Committee for the Prevention of Physical Disease and Mental Illness among Health Care Workers.

We used Pearson's correlation to investigate the relationships between job stress, various types of temperament and depressive symptoms. In order to examine the influence of temperament and job stress on depressive symptoms, the stepwise multiple regression analysis was applied. We also used a path-analytic approach to examine 
the causal relationships between temperament, job stress and depressive symptoms.

We started with a model that was close to saturated and then excluded pathways that were not statistically significant and did not contribute to the overall model fit as measured by 3 criteria:

1. Chi ${ }^{2}$ statistics for goodness of fit and associated p-value (significant p-value indicating poor fit).

2. Comparative Fit Index (CFI) (ranging from 0 to 1 , higher values indicating better fit).

3. Root Mean Square Error of Approximation (RMSEA). A RMSEA of 0.08 or less indicates a good fit and a RMSEA of 0.10 or more indicates a poor fit.

We used SPSS 11 (SPSS Inc., Chicago, IL, USA) for all analyses. Path-analytic models were evaluated using SPSS Amos Version 21.

\section{RESULTS}

Table 1 shows characteristics of the study subjects and mean and standard deviations of the 3 domains of job stress, 5 domain scores of the TEMPS-A and the depressive symptoms scores.

Table 2 shows the pairwise Pearson's correlation coefficients between job stress, temperament and depressive symptoms. Depressive symptoms significantly but modestly correlated with job stress $(\gamma=-0.23-0.30)$, while its correlations with various types of temperament, except for hyperthymic temperament, were significant and moderate $(\gamma=0.36-0.50)$.

Table 3 shows the influence of work-related factors, job stress and temperament on depressive symptoms. Overtime work, job control, and depressive and cyclothymic types of temperament were significantly correlated with depressive symptoms $(\beta=0.15, p<0.05 ; \beta=0.19, p<0.01 ; \beta=0.26$, $\mathrm{p}<0.001 ; \beta=0.32, \mathrm{p}<0.001$, respectively).

As shown by Pearson's correlations in Table 2 and by the results of the multiple linear regression in Table 3,
Table 1. Characteristics of the study group

\begin{tabular}{lc}
\hline \multicolumn{1}{c}{ Work-related variable } & $\begin{array}{c}\text { Respondents } \\
(\mathrm{N}=330)\end{array}$ \\
\hline Hours of work [n (\%)] & $313(94.8)$ \\
full-time & $13(3.9)$ \\
part-time & \\
Shift work [n (\%)] & $261(79.1)$ \\
rotation to nights & $9(2.7)$ \\
no rotation to nights & $60(18.2)$ \\
no shift work & \\
Job rank [n (\%)] & $19(5.8)$ \\
manager & $21(6.4)$ \\
middle manager & $287(87.0)$ \\
staff nurse & $32.89 \pm 8.47$ \\
Age (years) $(\mathrm{M} \pm \mathrm{SD})$ & $7.16 \pm 5.61$ \\
Overtime per week $(\mathrm{h})(\mathrm{M} \pm \mathrm{SD})$ & \\
Job stress (total) $(\mathrm{M} \pm \mathrm{SD})$ & $5.21 \pm 1.60$ \\
load & $7.88 \pm 1.86$ \\
control & $13.77 \pm 3.46$ \\
support & \\
Temperament type $(\mathrm{M} \pm \mathrm{SD})$ & $1.37 \pm 0.18$ \\
depressive & $1.25 \pm 0.21$ \\
cyclothymic & $1.19 \pm 0.17$ \\
hyperhtymic & $1.16 \pm 0.16$ \\
irritable & $1.22 \pm 0.20$ \\
anxious & $1.90 \pm 1.74$ \\
depressive symptoms &
\end{tabular}

$\mathrm{M}$ - mean; SD - standard deviation.

overtime work, job control, support, as well as depressive and cyclothymic types of temperament are significantly correlated with depressive symptoms. Both, the direct and indirect observed relationships are illustrated in the path analytic diagrams presented in Figure 2. The model including irritable and anxious types of temperament and job quantitative overload did not show a good fit, so we excluded those variables from the model.

Depressive and cyclothymic types of temperament directly $(\beta=0.67, p<0.001)$ contributed to depressive 
Table 2. Correlations between job stress factors, temperament and depressive symptoms

\begin{tabular}{|c|c|c|c|c|c|c|c|c|}
\hline \multirow{2}{*}{ Variable } & \multicolumn{8}{|c|}{ Pearson's correlations } \\
\hline & 1 & 2 & 3 & 4 & 5 & 6 & 7 & 8 \\
\hline \multicolumn{9}{|l|}{ Stress } \\
\hline \multicolumn{9}{|l|}{ 1. Load } \\
\hline 2. Control & -0.11 & & & & & & & \\
\hline 3. Support & 0.03 & $0.32^{* *}$ & & & & & & \\
\hline \multicolumn{9}{|l|}{ Temperament } \\
\hline 4. Depressive & $-0.25^{* *}$ & $0.16^{* *}$ & $0.16^{* *}$ & & & & & \\
\hline 5. Cyclothymic & $-0.15^{* *}$ & $0.17^{* *}$ & 0.05 & $0.42^{* *}$ & & & & \\
\hline 6. Hyperthymic & -0.07 & $-0.15^{* *}$ & $-0.13^{* *}$ & 0 & $0.32 * *$ & & & \\
\hline 7. Irritable & -0.08 & $0.16^{* *}$ & 0.02 & $0.36^{* *}$ & $0.68^{* *}$ & $0.42 * *$ & & \\
\hline 8. Anxious & $-0.17^{* *}$ & $0.14^{* *}$ & 0.10 & $0.55^{* *}$ & $0.64 * *$ & $0.15^{* *}$ & $0.56^{* *}$ & \\
\hline 9. Depressive symptoms & $-0.23^{* *}$ & $0.30^{* *}$ & $0.23^{* *}$ & $0.47^{* *}$ & $0.50^{* *}$ & 0.01 & $0.36^{* *}$ & $0.41^{* *}$ \\
\hline
\end{tabular}

** $\mathrm{p}<0.01$.

Table 3. Multiple regression coefficients for depressive symptoms

\begin{tabular}{lccc}
\hline \multicolumn{1}{c}{ Predictor } & $\begin{array}{c}\text { Depressive symptoms } \\
(\beta)\end{array}$ & $\mathrm{t}$ & $\mathrm{p}$ \\
\hline Age & 0.36 & 0.46 & 0.65 \\
Overtime & 0.15 & 2.07 & $0.04^{*}$ \\
Hours of work & -0.67 & -0.29 & 0.77 \\
Job rank & -0.98 & -1.27 & 0.21 \\
Shift work & 0.07 & 1.06 & 0.29 \\
Load & -0.29 & -0.26 & 0.79 \\
Control & 0.19 & 2.04 & $0.04^{*}$ \\
Support & 0.11 & 1.84 & 0.07 \\
Depressive & 0.26 & 4.04 & $0.00^{* * *}$ \\
Cyclothymic & 0.32 & 4.33 & $0.00^{* * *}$ \\
Hyperthymic & -0.09 & -1.60 & 0.11 \\
Irritable & 0.01 & 0.85 & 0.40 \\
Anxious & -0.04 & -0.84 & 0.41 \\
$\mathrm{R}$ & 0.58 & & \\
$\mathrm{R}^{2}$ & 0.33 & & \\
Adjusted $\mathrm{R}^{2}$ & 0.32 & & $* * *$ \\
$\mathrm{~F}$ & 26.96 & &
\end{tabular}

$\mathrm{R}$ - multiplecorrelation coefficient; $\mathrm{R}^{2}$ - coefficient of determination; $\beta$ - standardized coefficient.

$\mathrm{F}$ - Fisher value; $\mathrm{t}-\mathrm{t}$ ratio.

${ }^{*} \mathrm{p}<0.05 ;{ }^{* * *} \mathrm{p}<0.001$. 
Table 4. Pathways of the causal relationships between temperament, job stress and depressive symptoms

\begin{tabular}{lccc}
\hline \multicolumn{1}{c}{ Latent variable } & Standardized estimate & $\mathrm{t}$ & $\mathrm{p}$ \\
\hline Temperament $\rightarrow$ Depressive symptoms & 0.67 & 7.70 & $<0.001$ \\
Temperament $\rightarrow$ Job stress & 0.35 & 3.65 & $<0.001$ \\
Job stress $\rightarrow$ Depressive symptoms & 0.20 & 2.56 & $<0.050$ \\
Overtime work $\rightarrow$ Depressive symptoms & 0.11 & 2.44 & $<0.050$ \\
\hline
\end{tabular}

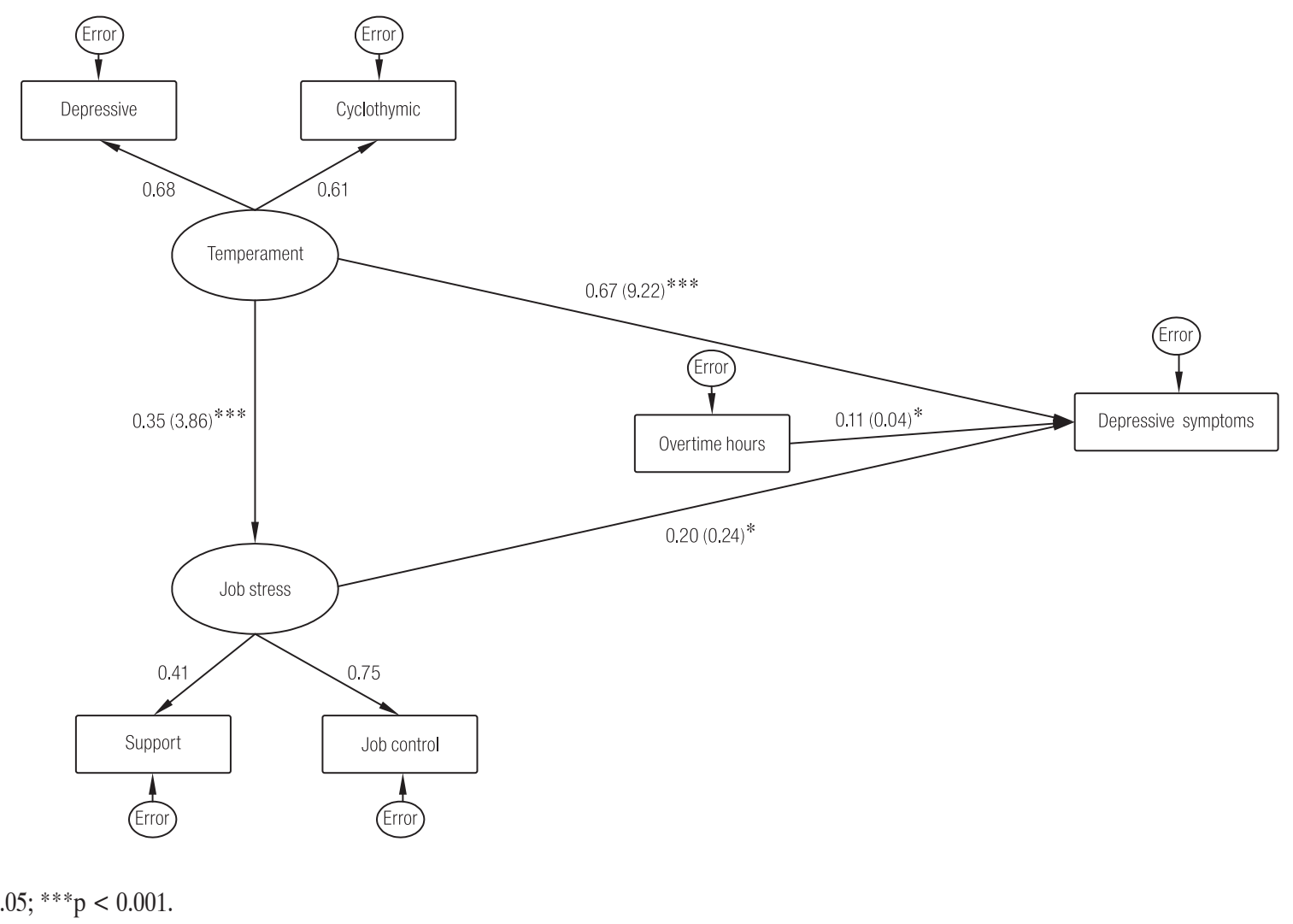

Fig. 2. Path analyses for the relationships between temperament, job stress and depressive symptoms

symptoms and were significantly associated with job stress $(\beta=0.35, \mathrm{p}<0.001)$. Similarly, indirect effect of depressive and cyclothymic types of temperament via job stress significantly contributed to the path-analytic models $(\beta=0.20, p<0.01)$. Overtime work directly contributed to depressive symptoms $(\beta=0.11, \mathrm{p}<0.05)$. The model presented in Figure 2 accounts for $58.3 \%$ of variance in depressive symptoms and $12 \%$ of variance in job stress. Table 4 shows standardized estimates of the model. The final path model shows good fit; the RMSEA of 0.035
(95\% CI: $0.000-0.076)$, insignificant $\mathrm{Chi}^{2}\left(\mathrm{x}^{2}=12.65\right.$, $\mathrm{p}=0.179)$ and the CFI of 0.986 .

\section{DISCUSSION}

In our path-analytic model (Figure 2), the considered types of temperament influenced depressive symptoms via job stress both, directly and indirectly. Health care professionals should pay special attention, in particular, to nurses with depressive or cyclothymic types of temperament, 
and help them cope better with job stress. As shown in Table 3 , temperament may have greater influence on depressive symptoms than work-related predictors and job stress. The present findings are in accordance with both, studies of Tei-Tominaga et al. [21] and Matsumoto et al. [15]. In the study of Matsumoto et al. [15], depressive, cyclothymic and anxious types of temperament might be risk factors for mood disorders. In the study of Tei-Tominaga et al. [21], cyclothymic and anxious types of temperament were high risk factors for depressive symptoms measured by the 12-item General Health Questionnaire (GHQ-12), but depressive temperament was not. In our study, depressive and cyclothymic types of temperament significantly influenced depressive symptoms, whereas anxious temperament did not.

We have measured depressive symptoms using the screening scale of items from the Ministry of Health, Labour and Welfare of Japan, which did not always diagnose major depressive disorder. Different sample characteristics and different assessment measures used may lead to these discrepancies.

Irritable temperament did not show significant influence on depressive symptoms, which was similar to the previous studies [9,14,15,21]. Kraepelin [9] considered irritable temperament as a mixture of the dispositions of depression and mania. Matsumoto et al. [15] and Akiskal et al. [14] suggest that irritable temperament may represent a subtype of depressive, cyclothymic and anxious types of temperament in both Japanese and Italian population. Our data concerning female nurses in the Japanese general hospital led to a similar conclusion. Moreover, our findings partially supported the theoretical concept of Kretschmer [10] that cyclothymic is the premorbid temperament of mood disorder.

However, our study has some limitations. Firstly, the sample size was small and limited to nurses in only one hospital. Secondly, we measured depressive symptoms using only 5 screening items. Thirdly, we did not measure non-work factors, which may have influence on depressive symptoms. More research with larger samples using a scale that assesses mood disorder in detail is needed. In spite of the limitations, our study is the first report of the fitness of modeling causality between temperament, job stress and depressive symptoms, and provides useful information for occupational and mental health services.

Depressive and cyclothymic temperament types significantly, directly and indirectly influenced depressive symptoms via job stress among female nurses in the general hospital. Health care professionals should consider temperament, especially depressive and cyclothymic temperament types, in order to help employees cope better with their job stress. Intervention support such as psychological education or stress management program including relaxation, self-observation, coping with depression and excessive work commitment ("high need for control"), management of conflicts with a supervisor and with a coworker may change perception of job stress and reduce the risk of depressive state in nurses with depressive or cyclothymic types of temperament. Further research concerning effective intervention to help employees cope better accordingly with their job stress is necessary.

\section{REFERENCES}

1. Bagaajav A, Myagmarjav S, Nanjid K, Otgon S, Chae Y. Burnout and job stress among Mongolian doctors and nurses. Ind Health. 2011;49(5):582-8, http://dx.doi.org/10.2486/indhealth.MS1256.

2. Bonneterre V, Liaudy S, Chatellier G, Larg T, de Gandemaris R. Reliability, validity, and health issues arising from questionnaires used to measure Psychosocial and Organizational Work Factors (POWFs) among hospital nurses: A critical review. J Nurs Meas. 2008;16(3):207-30, http://dx.doi. org/10.1891/1061-3749.16.3.207.

3. Griep RH, Rotenberg L, Vasconcellos AG, Landsbergis P, Comana CM, Alves MG. The psychometric properties of demand-control and effort-reward imbalance scales among Brazilian nurses. Int Arch Occup Environ Health. 2009;82(10):1163-72, http://dx.doi.org/10.1007/ s00420-009-0460-3. 
4. Joivet A, Caroly S, Ehlinger V, Kelly-lrving M, Delpierre C, Balducci $\mathrm{F}$, et al. Linking hospital workers' organizational work environment to depressive symptoms: A mediating effect of effort-reward imbalance? The ORSOSA study. Soc Sci Med. 2010;71(3):534-40, http://dx.doi.org/10.1016/j.socscimed.2010.04.003.

5. Kikuchi Y, Nakaya M, Ikeda M, Narita K, Takeda M, Nishi M. Effort-reward imbalance and depressive state in nurses. Occup Med. 2010;60:231-3, http://dx.doi.org/ 10.1093/occmed/kqp167.

6. Pratt M, Kerr M, Wong C. The impact of ERI, burnout, and caring for SARS patients on hospital nurses' self-reported compliance with infection control. Can J Infect Control. 2009;24(3):167-72.

7. Schulz M, Damkroger A, Heins C, Wehlitz L, Lohr M, Driessen $\mathrm{M}$, et al. Effort-reward imbalance and burnout among German nurses in medical compared with psychiatric hospital settings. J Psychiatr Ment Health Nurs. 2009;16(3): 225-33, http://dx.doi.org/10.1111/j.1365-2850.2008.01355.x.

8. Schulz M, Damkronger A, Voltmer E, Lowe B, Driessen M, Ward M, et al. Work-related behaviour and experience pattern in nurses: Impact on physical and mental health. J Psychiatr Ment Health Nurs. 2011;18(5):411-7, http://dx.doi. org/10.1111/j.1365-2850.2011.01691.x.

9. Kraepelin E. [Psychiatry - A textbook for students and physicians]. Leipzig: Johann Ambrosius Barth; 1913. German.

10. Kretschmer E. [Body type and character]. Berlin: Springer; 1955. p. 21-22. German.

11. Tellenbach H. [Melancholy]. Berlin: Springer; 1961, http://dx.doi.org/10.1007/978-3-662-12458-1. German.

12. Shimoda K. On manic depressive illness. Yonago Med Mag. 1949;2:1-2.

13. Akiskal H, Placidi G, Signoretta S, Liguori A, Gervasi R, Maremmami I, et al. TEMPS-I: delineating the most discriminant traits of the cyclothymic, depressive, irritable, and hyperthymic temperaments in a nonpatient population. J Affect Disord. 1998;51:7-19, http://dx.doi.org/10.1016/ S0165-0327(98)00152-9.
14. Akiskal H, Akiskal K, Hayakal R, Manning J, Connor P. TEMPS-A: Progress towards validation of a self-rated clinical version of the temperament evaluation of the Memphis, Pisa, Paris, and San Diego autoquestionnaire. J Affect Disord. 2005;85:3-16, http://dx.doi.org/10.1016/ j.jad.2004.12.001.

15. Matsumoto S, Akiyama T, Tsuda H, Miyake Y, Kawamura Y, Noda $T$, et al. Reliability and validity of TEMPS-A in a Japanese non-clinical population: Application to unipolar and bipolar depressives. J Affect Disord. 2005;85:85-92, http://dx.doi.org/10.1016/j.jad.2003. 10.001 .

16. Sakai Y, Akiyama T, Miyake Y, Kawamura Y, Tsuda H, Kurabayashi L, et al. Temperament and job stress in Japanese company employees. J Affect Disord. 2005;85:101-12, http://dx.doi.org/10.1016/j.jad.2004.03.012.

17. Tei-Tominaga M, Akiyama T, Miyake Y, Sakai Y. The relationship between temperament, job stress and overcommitment: A cross-sectional study using the TEMPS-A and a scale of ERI. Ind Health. 2009;47:509-17, http://dx.doi. org/10.2486/indhealth.47.509.

18. Kikuchi Y, Nakaya M, Ikeda M, Takeda M, Nishi M. Temperaments and job stress in female nurses. Occup Med. 2013;63:123-8.

19. Jurado D, Gurpegui M, Moreno O, Fernandez MC, Luna JD, Galvez R. Association of personality and work conditions with depressive symptoms. Eur Psychiatry. 2005;20:213-22, http://dx.doi.org/10.1016/j.eurpsy.2004.12.009.

20. Paterniti S, Niedhammer I, Lang T, Consoli SM. Psychosocial factors at work, personality traits and depressive symptoms; longitudinal results from the GAZEL Study. Br J Psychiatry. 2002;181:111-7.

21. Tei-Tominaga M, Akiyama T, Sakai Y. Effect of affective temperaments assessed by the TEMPS-A on the relationship between work-related stressors and depressive symptoms among workers in their twenties to forties in Japan. Depression Res Treat. 2012;2012, http://dx.doi. org $/ 10.1155 / 2012 / 469384$. 
22. Shimomitsu T, Yokoyama K, Ohno H, Maruta T, Tanigawa $\mathrm{T}$. [Manual of the brief job stress questionnaire. Reports on the study of job stress and its effects on health in the workplace: The research grant for the prevention of workrelated diseases from the Japan Ministry of Labor]. Tokyo: The Ministry of Labor; 2000, p. 17-27. Japanese.
23. Fujisawa D, Tanaka E, Sakamoto S, Neichi K, Nakagawa A, Ono Y. The development of a brief screening instrument for depression and suicidal ideation for elderly: The depression and suicide screen. Psychiatry Clin Neurosci. 2005;59:634-8, http://dx.doi.org/10.1111/j.14401819.2005.01429.x.

This work is available in Open Access model and licensed under a Creative Commons Attribution-NonCommercial 3.0 Poland License - http://creativecommons.org/ licenses/by-nc/3.0/pl/deed.en. 